\title{
A polysomnographic study in young psychiatric inpatients: major depression, anorexia nervosa, bulimia nervosa
}

\author{
Christoph J. Lauer, Jürgen-Christian Krieg, Dieter Riemann *, Jürgen Zulley \\ and Mathias Berger* \\ Max-Planck-Institute of Psychiatry, Munich, F,R.G.
}

(Received 3 March 1989)

(Revision received 24 July 1989)

(Accepted 1 August 1989)

\section{Summary}

The baseline EEG sleep patterns of 10 young depressed patients, 20 patients with anorexia nervosa, 10 patients with bulimia nervosa, and 10 healthy subjects were found to be indistinguishable, except for an increased REM density in the depressed patients. In eating disorder patients, a concomitant major depressive episode had no influence on EEG sleep. The results of the cholinergic REM sleep induction test revealed a significantly faster induction of REM sleep in the depressed patients when compared with the eating disorder patients and the control subjects. This indicates a subthreshold hypersensitivity of the REM sleep triggering cholinergic transmitter system in depressives, but not in eating disorder patients.

Key words: Major depression; Anorexia nervosa; Bulimia nervosa; Age; EEG sleep; REM sleep induction test

\section{Introduction}

Certain alterations in the EEG sleep patterns of patients with major depression are alleged to be characteristic of this psychiatric disorder. Besides a shallow sleep quality and a reduced amount of slow-wave sleep, the most typical alterations are

Address for correspondence: Dr. C.J. Lauer, Department of Psychiatry, University of Freiburg, Hauptstrasse 5, 7800 Freiburg, F.R.G.

* Present address: Central Institute of Mental Health, Mannheim, F.R.G. related to rapid eye movement (REM) sleep. The time between sleep onset and the beginning of the first REM sleep period (REM latency) is shortened and the density of the rapid eye movements during REM sleep (REM density) is increased (for overview see Gillin et al., 1984; Reynolds and Kupfer, 1987). These altered EEG sleep patterns are attributed to neuroendocrine and CNS transmitter receptor disturbances and are therefore regarded as a biological marker for this disorder. The neurochemical model of sleep regulation (Hobson et al., 1975, 1986; McCarley, 1982), proposing a reciprocal interaction of central aminergic (REM-'off') and cholinergic (REM-'on') neurons 
in triggering the cyclic alteration of non-REM and REM sleep, assumes a relative overactivity of the cholinergic system in depression causing the early onset of REM sleep as well as the enhanced REM density (for overview see Sitaram et al., 1984). This point of view is in accordance with the cholinergic-aminergic imbalance theory of affective disorders (Janowsky et al., 1972).

Recent studies investigating the polysomnograms in prepubertal and adolescent depressives, however, failed to observe the described EEG sleep alterations, i.e., a shortened REM latency (Taub et al., 1978; Kupfer et al., 1979; Puig-Antich et al., 1982; Young et al., 1982; Hawkins et al., 1985; Goetz et al., 1987; Appelboom-Fondu et al., 1988; Kempenears et al., 1988; Kupfer et al., 1989). Furthermore, in healthy subjects the REM latency decreases with increasing age (Feinberg et al., 1967; Gillin et al., 1981) and a shortened REM latency is reported to occur occasionally in healthy seniors (Spiegel, 1981). These observations question the specificity of the EEG sleep patterns allegedly characteristic of major depression. On the other hand, one might wonder how far the altered sleep patterns in major depression may be attributed to a 'premature aging' of the basic neuroendocrine processes organizing sleep patterns.

Another aspect in investigating the polysomnograms of young depressed patients is provided by the ongoing discussion about the existence of a significant biological link between major depression and eating disorders, such as anorexia nervosa and bulimia nervosa (for overview see Swift et al., 1986; Strober and Katz, 1987). Several studies focused on the EEG sleep pattern in eating disorder patients. A shortened REM latency in at least a subgroup of patients with anorexia nervosa or bulimia was reported by Neil et al. (1980), Katz et al. (1984), and Walsh et al. (1985). In the latter two studies, all patients exhibiting a shortened REM latency suffered from a significant depressive mood disturbance. On the other hand, Levy et al. (1987, 1988), Hudson et al. (1987) and Lauer et al. (1988) found no altered REM sleep patterns in anorexic and bulimic patients, regardless of the coexistence of a minor or major depression. However, the majority of these investigations had the disadvantage of not including a comparison group of patients with major depression. In an outpatient study Hudson et al. (1987) reportcd a lower sleep continuity and an increased REM density in the depressed patients as compared to the bulimic patients. Mean REM latency did not distinguish among these groups.

A further possibility in testing the hypothesis of a common biological link between major depression and eating disorder is provided by the cholinergic REM sleep induction test (RIT) which is based on both the cholinergic-aminergic imbalance theory of depression and the neurochemical model of sleep regulation described above. Several studies have demonstrated that the REM sleep initiating effect of a cholinergic agent (arecoline, physostigmine) is significantly more pronounced in patients with major depression than in healthy volunteers (for overview see Sitaram et al., 1984). In eating disorder patients the RIT was performed only by Sitaram et al. (1984) using the arecoline paradigm. Sixty-six percent of the anorexic patients with a concomitant major depression were classified as arecoline-supersensitive, whereas only $12 \%$ of the anorexic patients without such a concomitant disorder showed an abnormal REM sleep response.

Spiegel (1984) introduced a further cholinergic agent, the spiropiperidyl derivate RS 86 (Sandoz), into sleep research. Because of its pharmacokinetic properties (Palacios et al., 1986) and the resulting methodological advantages (Berger et al., 1989), RS 86 seems to be more suitable than physostigmine or arecoline in testing the assumption of a cholinergic hypersensitivity in major depressive disorder. In healthy volunteers, the REM sleep inducing properties of RS 86 were proved by Spiegel (1984) and Riemann et al. (1988). Berger et al. $(1985,1989)$ demonstrated that the effect of RS 86 on REM sleep regulation was significantly more pronounced in patients with major depression than in patients with other psychiatric disorders and healthy volunteers, supporting the hypothesis of a functional hypersensitivity of the cholinergic system during depression.

The current comparative study examines the polysomnograms of young depressed inpatients, of eating disorder inpatients (anorexia nervosa, bulimia nervosa), and of healthy subjects in order to determine whether there are (a) differences in 
baseline EEG sleep patterns and (b) differential effects of the cholinergic drug RS 86 on the REM sleep parameters studied in a subgroup of the patient samples and the healthy volunteers.

\section{Methods}

\section{Subjects}

The following four groups of subjects, matched for age and gender distribution, were studied.

Group 1 consisted of 10 inpatients (eight female, two male) with a major depression, melancholic subtype (according to DSM-III-R criteria, American Psychiatric Association, 1987). Ages ranged from 18 to 26 years. The mean ( \pm SD) duration of the current depressive episode was $3.5 \pm 1.4$ months and the number of previous episodes was $1.9 \pm 0.9$. The patients had no anorexic or bulimic symptoms and their body weights ranged from 91 to $122 \%$ of ideal body weight (IBW; according to the tables of the Metropolitan Life Insurance Company, 1959).

Group 2 consisted of 20 inpatients (19 female, one male) with anorexia nervosa (according to both the criteria of Feighner et al., 1972, and the broader DSM-III-R criteria) with ages ranging from 16 to 27 years. Their body weights ranged from 58 to $80 \%$ of IBW (mean \pm SD: $70 \pm 6 \%$ ). On average, their illness lasted for $3.3 \pm 2.8$ years. Nine patients (45\%) had a concomitant major depressive episode, all of non-melancholic subtype.

Group 3 consisted of 10 inpatients (all female) with bulimia nervosa (according to both the criteria of Russell, 1983, and the broader DSM-III-R criteria) with ages ranging from 18 to 27 years. Their body weights were $85-120 \%$ of IBW (mean: $98.0 \pm 15.5 \%)$. The mean duration of illness was $6.5 \pm 2.1$ years. Five patients $(50 \%)$ had a current episode of major depression, all of nonmelancholic subtype.

Group 4 consisted of 10 normal-weight healthy volunteers (nine female, one male; age range 18-27 years, range of body weights $85-104 \%$ of IBW). A thorough screening including an extensive semistructured psychiatric interview ensured that they were free of physical and personal/family history of psychiatric disorders; further, their eating habits were 'normal' (no dietary schedule, no food selection).

In the patients the diagnosis of major depression was assessed by the Composite International Diagnostic Interview (CIDI; German version, Semler et al., 1987). Severity of depressive symptomatology was rated by the Inpatient Multidimensional Psychiatric Scale - second-order factor 'depressive symptomatology' (IMPS; Lorr et al., 1962 ; a cut-off value of $15 \%$ of the theoretically possible maximum score distinguishes well between depressed and non-depressed psychiatric patients; Berger et al., 1982).

The medication-free period prior to the polysomnographic investigation was 8-21 days in five of the melancholic depressives, at least 6 months in the remaining five melancholic depressives, and at least 3 months in the eating disorder patients. None of the healthy volunteers had ever been treated with psychoactive substances.

Sleep

All subjects slept for three consecutive nights in the sleep research unit of the Max-Planck-Institute for Psychiatry, Munich. After two nights, serving for adaptation, sleep was recorded between 'lights out' $(23.15 \mathrm{~h})$ and 'lights on' $(6.30 \mathrm{~h})$ using standard procedures (EEG, EOG, EMG). Records were then scored visually according to standard criteria (Rechtschaffen and Kales, 1968) by two experienced raters blind to the subjects' diagnoses. Definitions of sleep measurement have previously been described in detail (Lauer et al., 1988).

\section{Cholinergic REM sleep induction test (RIT)}

Out of the total group of eating disorder patients, six anorexic patients (five female, one male; age $22.5 \pm 3.1$ years; two patients with a concurrent non-melancholic major depressive episode) and six bulimic patients (all female; age $21.5 \pm 2.7$ years; four patients with a concurrent nonmelancholic major depressive episode) participated in the RIT. Furthermore, seven patients with a major depression (five female, two male; age $25.7 \pm 6.8$ years; four were of melancholic subtype) and 12 healthy volunteers (seven female, five male; age $23.3 \pm 2.8$ years) were investigated (the data of five depressives and of seven control subjects were selected from another study on the 
basis of an age under 35 years; Riemann et al., 1988; Berger et al., 1989). In the depressives and the bulimic patients the RIT was performed immediately after the baseline period. For medical reasons, the RIT was performed in the anorexic patients after they had reached a body weight of at least $80 \%$ of IBW (mean IBW: $85.5 \pm 5.1 \%$ ). In the eating disorder patients and the control subjects, the RIT was performed by administering orally $1.5 \mathrm{mg}$ RS 86 and placebo, respectively, at $22.00 \mathrm{~h}$ in randomized order. In the depressed patients, the drug night was embedded between two placebo nights in fixed order (by random selection, data analyses include a placebo-RS 86 regime in four depressives, and an RS 86-placebo regime in the remaining three depressed patients). Sleep was recorded as mentioned above. The subjects were informed in detail about the possible side effects of the drug and written informed consent was given.

\section{Statistics}

Data were analyzed by means of an ANOVA (baseline EEG sleep) and a MANOVA (RIT). If the variance was inhomogeneous (Bartlett-Box $F$ ), then the analysis of the respective parameters was repeated by means of a Kruskal-Wallis ANOVA. Two-sample comparisons were done using Student's $t$-test; if the variance proved to be inhomogeneous, then the corrected form as recommended by Welch (cited in Pfanzagl, 1962) was assessed. The Pearson correlation coefficient served to assess correlations. The level of significance was set at $5 \%$ (two-tailed).

\section{Results}

As expected, the anorexic patients had a lower body weight than the other three groups ( $F=35.5$, $d f=3, \quad P<0.001)$. The depressive symptomatology (IMPS) was most severe in the melancholic depressives (IMPS: $56.4 \% \pm 13.3 \%$ of maximum value; $F=37.5, d f=2, P<0.001)$. The patients with bulimia nervosa showed a more depressed mood than the patients with anorexia nervosa (IMPS: $29.7 \% \pm 8.0 \%$ of maximum value vs. $19.5 \%$ $\pm 8.4 \%$ of maximum value; $t=3.2, d f=28, P<$ $0.01)$.

\section{Baseline EEG sleep}

Measurements of sleep continuity, sleep architecture and REM latency did not distinguish between the three patient samples and the healthy controls (a detailed description of data obtained in the anorexic and bulimic patients is given in Lauer et al., 1988). The only sleep parameters significantly differing between the groups were the REM density of the first REM period ( $F=3.22$, $d f=3, P<0.05)$ and the mean REM density ( $F$ $-6.37, d f-3, P<0.001$ ). Both measurements were highest in the patients with melancholic depression.

In a further analysis the sample of the eating disorder patients was dichotomized according to the presence/absence of a concurrent DSM-III-R diagnosis of a major depressive episode. The results obtained are presented in Table 1. Depressive symptomatology (as measured by the IMPS) was most severe in the melancholic depressives; the eating disorder patients with a concomitant major depression were rated to be less depressed than the melancholic depressives $(t=5.6, d f=22$, $P<0.001$ ) but only tended to display a more deteriorated mood when compared with the eating disorder patients without such an additional DSM-III-R diagnosis $(t=1.6, d f=28, P<0.12)$.

Again, sleep continuity and sleep architecture did not differ between the groups. The mean REM latency was shortest in the melancholic depressed patients (Fig. 1). This observation, however, was not confirmed by statistical analysis (Table 1). Calculating the frequencies of shortened REM latency ( $<45 \mathrm{~min}$; indicated by the dotted line in Fig. 1) it was found that the melancholic depressives exhibited a shortened REM latency more often than the other three groups $\left(\chi^{2}=9.69\right.$, $d f=3, P<0.025$ ). Again, the REM density of the first REM period and the mean REM density were significantly increased in the melancholic depressives when compared to the eating disorder groups $(t>2.5, P<0.05)$. In comparison with the control subjects, the REM density of the melancholic depressives only tended to be increased (first REM density; $t=1.76, d f=18, P<$ 0.10 ; mean REM density: $t=1.98, d f=18, P<$ $0.07)$.

Dichotomizing the eating disorder group on the basis of severity of depressive symptomatology 
TABLE 1

STATISTICAL RESULTS (MEAN $\pm S D$, ANOVA) OF CLINICAL CHARACTERISTICS AND SLEEP PARAMETERS IN PATIENTS WITH MAJOR DEPRESSION, EATING DISORDER PATIENTS WITH AND WITHOUT A CONCOMITANT MAJOR DEPRESSION, AND HEALTHY SUBJECTS

\begin{tabular}{|c|c|c|c|c|c|}
\hline & \multirow{2}{*}{$\begin{array}{l}\text { Depression } \\
(n=10)\end{array}$} & \multicolumn{2}{|c|}{ Eating disorder } & \multirow{2}{*}{$\begin{array}{l}\text { Control } \\
\text { subjects } \\
(n=10)\end{array}$} & \multirow[t]{2}{*}{ ANOVA } \\
\hline & & $\begin{array}{l}\text { Depressed }^{4} \\
(n=14)\end{array}$ & $\begin{array}{l}\text { Non-depressed } \\
(n=16)\end{array}$ & & \\
\hline Age (years) & $22.7 \pm 2.2$ & $21.9 \pm 3.1$ & $21.6 \pm 3.4$ & $23.1 \pm 3.1$ & $F(3)-0.62$ \\
\hline Body weight (of IBW) & $103.4 \pm 12.2$ & $79.4 \pm 16.5$ & $79.6 \pm 17.3$ & $96.0 \pm 5.9$ & $F(3)=8.18 P<0.001$ \\
\hline $\begin{array}{l}\text { Depressive symptomatology } \\
\text { (IMPS; } \% \text { max. value) }\end{array}$ & $51.3 \pm 12.5$ & $29.7 \pm 8.0$ & $19.5 \pm 8.4$ & - & $F(2)=30.65 P<0.001$ \\
\hline \multicolumn{6}{|l|}{ Sleep continuity } \\
\hline Sleep period time (SPT, min) & $416.5 \pm 33.2$ & $419.0 \pm 24.8$ & $399.5 \pm 29.6$ & $413.7 \pm 17.0$ & $F(3)=1.55$ \\
\hline Sleep efficiency $(\%)$ & $89.2 \pm 9.2$ & $90.1 \pm 6.7$ & $88.8 \pm 6.9$ & $93.2 \pm 4.2$ & $F(3)=0.94$ \\
\hline Sleep onset latency & $21.1 \pm 15.9$ & $19.6 \pm 14.6$ & $15.3 \pm 15.1$ & $19.0 \pm 10.6$ & $F(3)=0.40$ \\
\hline Intermittent wake time (min) & $24.3 \pm 45.0$ & $19.8 \pm 20.6$ & $15.7 \pm 20.1$ & $7.8 \pm 11.0$ & $F(3)=0.75$ \\
\hline \multicolumn{6}{|l|}{ Sleep architecture } \\
\hline Slow-wave sleep (\%SPT) & $21.2 \pm 8.6$ & $23.0 \pm 10.1$ & $16.7 \pm 8.4$ & $19.6 \pm 7.6$ & $F(3)=1.36$ \\
\hline REM sleep (\%SPT) & $22.6 \pm 8.5$ & $18.3 \pm 5.7$ & $20.7 \pm 6.8$ & $19.4 \pm 3.7$ & $F(3)=0.94$ \\
\hline \multicolumn{6}{|l|}{ REM sleep } \\
\hline RE.M latency (min) & $56.4 \pm 29.8$ & $76.8 \pm 241$ & $78.3 \pm 66.2$ & $72.0 \pm 31.5$ & $F(3)=0.58$ \\
\hline $\begin{array}{l}\text { Duration of first REM period } \\
\text { (min) }\end{array}$ & $17.8 \pm 19.5$ & $12.4 \pm 8.1$ & $19.5 \pm 19.5$ & $14.6 \pm 8.6$ & $F(3)=0.61$ \\
\hline First REM density $(\%)$ & $31.1 \pm 13.0$ & $19.3 \pm 9.3$ & $20.4 \pm 8.9$ & $22.4 \pm 8.5$ & $F(3)=3.24 P<0.05$ \\
\hline Mean REM density ( & $41.2 \pm 9.7$ & $29.1 \pm 9.7$ & $24.2 \pm 7.6$ & $32.2 \pm 10.5$ & $F(3)=7.18 P<0.001$ \\
\hline
\end{tabular}

a Concomitant major depression according to DSM-III-R criteria.

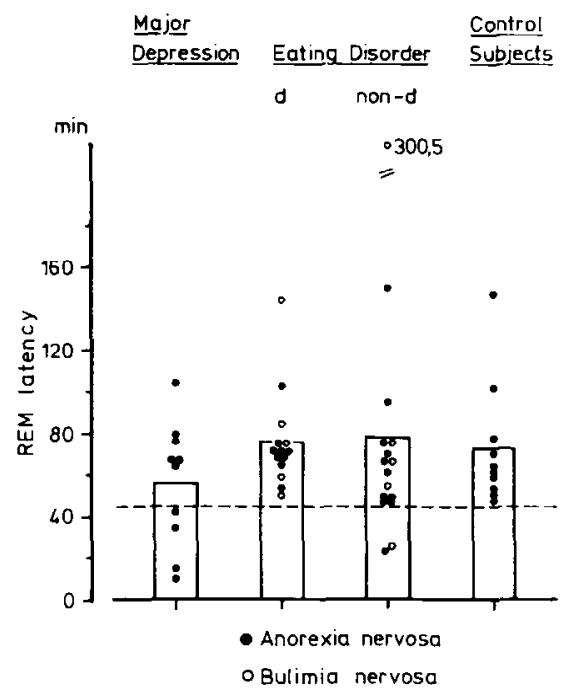

Fig. 1. REM latency during baseline night in 10 patients with major depression, melancholic subtype, 14 eating disorder patients with a concomitant DSM-III-R diagnosis of a major depression (d), 16 non-depressed eating disorder patients (nond), and 10 healthy volunteers. The bars represent the means. The dotted line indicates the cut-off value (45 min) of REM latency. (using a cut-off IMPS value of $15 \%$ of maximum value) no significant differences were found between these two groups. When compared to the melancholic depressives, both eating disorder samples showed a significantly lower REM density $(t>2.50, P<0.05)$.

Re-examining these observations by means of non-parametric methods (Kruskal-Wallis ANOVA) the results did not change.

No significant correlation coefficients were observed between sleep measurements and severity of depressive symptomatology or body weight in any of the groups. Age was negatively correlated with the relative amount of slow-wave sleep in the eating disorder patients without a concomitant depressive episode $(r=-0.64, P<0.01)$; in all other samples this association approximated the level of significance $(P<0.10)$. Further, age was negatively associated with REM latency in the melancholic depressives $(r=-0.66, P<0.05)$.

Cholinergic REM sleep induction test

Table 2 summarizes the descriptive statistics of 
TABLE 2A

STATISTICAL RESULTS (MEAN $\pm S D$; REPEATED-MEASUREMENT ANALYSIS) OF EEG SLEEP PARAMETERS DURING THE PLACEBO AND DRUG (RS 86) NIGHTS IN PATIENTS WITH MAJOR DEPRESSION, EATING DISORDER PATIENTS AND CONTROL SUBJECTS

\begin{tabular}{|c|c|c|c|c|c|c|}
\hline & \multicolumn{2}{|c|}{ Eating disorder $(n-12)$} & \multicolumn{2}{|c|}{ Depression $(n=7)$} & \multicolumn{2}{|c|}{ Control subjects $(n=12)$} \\
\hline & Placebo & $\mathrm{KS} 86$ & Placebo & RS 86 & Placebo & $\mathrm{RS} 86$ \\
\hline Sleep efficiency $(\%)$ & $87.5 \pm 10.9$ & $87.3 \pm 11.3$ & $86.7 \pm 21.0$ & $85.4 \pm 10.4$ & $94.0 \pm 4.0$ & $92.3 \pm 3.3$ \\
\hline Slow-wave slecp (\%SPT) & $22.7 \perp 8.1$ & $10.9 \pm 9.8 * * *$ & $13.8 \pm 8.7$ & $9.9 \perp 7.7$ & $19.6 \pm 7.7$ & $14.5 \pm 7.7 *$ \\
\hline REM sleep (\%SPT) & $20.3 \pm 4.2$ & $22.0 \pm 5.2$ & $20.5 \pm 2.9$ & $23.5 \pm 5.5^{*}$ & $18.7 \pm 2.4$ & $21.6 \pm 3.1 *$ \\
\hline REM latency (min) & $75.2 \pm 22.2$ & $53.3 \pm 22.5 * *$ & $91.6 \pm 34.4$ & $17.5 \pm 25.8 * * *$ & $72.8 \pm 27.6$ & $54.5 \pm 19.3^{*}$ \\
\hline First REM period (min) & $14.3 \pm 8.2$ & $19.9 \pm 13.8$ & $10.7 \pm 7.3$ & $15.5 \pm 11.4$ & $12.2 \pm 9.5$ & $17.7 \pm 12.7$ \\
\hline First REM density $(\mathscr{R})$ & $21.7 \pm 7.1$ & $26.4 \pm 11.9$ & $28.8 \pm 18.8$ & $46.6 \pm 19.7 * * *$ & $26.2 \pm 13.4$ & $26.0 \pm 11.6$ \\
\hline Mean REM density (\%) & $28.9+4.2$ & $29.0+10.2$ & $36.6+17.7$ & $41.0+18.4$ & $34.0+12.2$ & $33.6 \pm 10.2$ \\
\hline
\end{tabular}

Repeated-measurement analysis: ${ }^{*} P<0.05 ;{ }^{*} P<0.01 ;{ }^{*} * P<0.001$.

TABLE 2B

MAIN EFFECTS (MANOVA)

\begin{tabular}{|c|c|c|c|c|c|}
\hline & \multirow{2}{*}{$\frac{\text { Diagnosis }}{F(2) P}$} & \multicolumn{2}{|c|}{ Treatment } & \multicolumn{2}{|c|}{ Interaction } \\
\hline & & $F(1)$ & $P$ & $F(2)$ & $P$ \\
\hline $\begin{array}{l}\text { Sleep efficiency } \\
(\%)\end{array}$ & 1.52 & 0.54 & & 0.11 & \\
\hline $\begin{array}{l}\text { Slow-wave sleep } \\
\text { (\%SPT) }\end{array}$ & 1.24 & 25.84 & $<0.001$ & 3.52 & $<0.05$ \\
\hline $\begin{array}{l}\text { REM sleep } \\
\text { (\%SPT) }\end{array}$ & 0.66 & 12.43 & $<0.005$ & $5 \quad 0.37$ & \\
\hline $\begin{array}{l}\text { REM latency } \\
\text { (min) }\end{array}$ & 0.56 & 57.16 & $<0.001$ & 10.77 & $7<0.001$ \\
\hline $\begin{array}{l}\text { First REM period } \\
\text { (min) }\end{array}$ & 0.48 & 4.80 & $<0.05$ & 0.01 & \\
\hline $\begin{array}{l}\text { First REM density } \\
(\%)\end{array}$ & $2.92<0.07$ & 13.08 & $<0.005$ & 5.96 & $6<0.01$ \\
\hline $\begin{array}{l}\text { Mean REM density } \\
\text { (范) }\end{array}$ & 1.70 & 0.9 & & 20.99 & \\
\hline
\end{tabular}

the placebo and the drug night as well as the results of the MANOVA (Table 2B) and the repeated-measurement analysis (Table 2A). During the placebo night no significant group effect was observed, replicating the results obtained during the baseline period. After administering RS 86 (treatment effects) the relative amount of slowwave sleep (SWS) was reduced, whereas the relative amount of REM sleep was increased. Mean REM latency was highly significantly shortened during the drug night and both the duration and the REM density of the first REM period were increased. Interaction effects (group $\times$ treatment) were observed with regard to the relative amount of SWS as well as to REM latency and the first REM density.

In order to analyze the differential effects of RS 86 on sleep patterns in more detail, a repeated-measurement analysis was computed (within-group test: placebo vs. RS 86). During the drug night, the relative amount of SWS was reduced in the eating disorder patients and the control subjects, but not in the depressed patients. The increase of the relative amount of REM sleep during the drug night was proved in the depressives and the control subjects. REM latency was significantly shortened in each sample. This effect of RS 86, however, was significantly more pronounced in the depressives than in the eating disorder patients and the control subjects ( $F=$ 7.38, $d f-2, P<0.005$; see $\Gamma$ ig. 2 ). In the latter two samples mean REM latencies were similar. Five $(72 \%)$ of the seven depressed patients, but only one eating disorder patient $(8 \%$; a patient with bulimia nervosa not suffering from a concomitant major depressive episode), displayed a sleep onset REM period (REM latency $<20 \mathrm{~min}$; see Fig. 2). The REM density of the first REM period was significantly increased in the depressed patients when compared to the eating disorder patients and the control subjects $(F=5.72, d f=2$, $P<0.01$ ).

Comparing the eating disorder patients with and without a concomitant major depressive episode, no differential effect was found. In particular, mean REM latencies of these two samples were similar during the placebo night ( $70 \pm 7$ vs. 


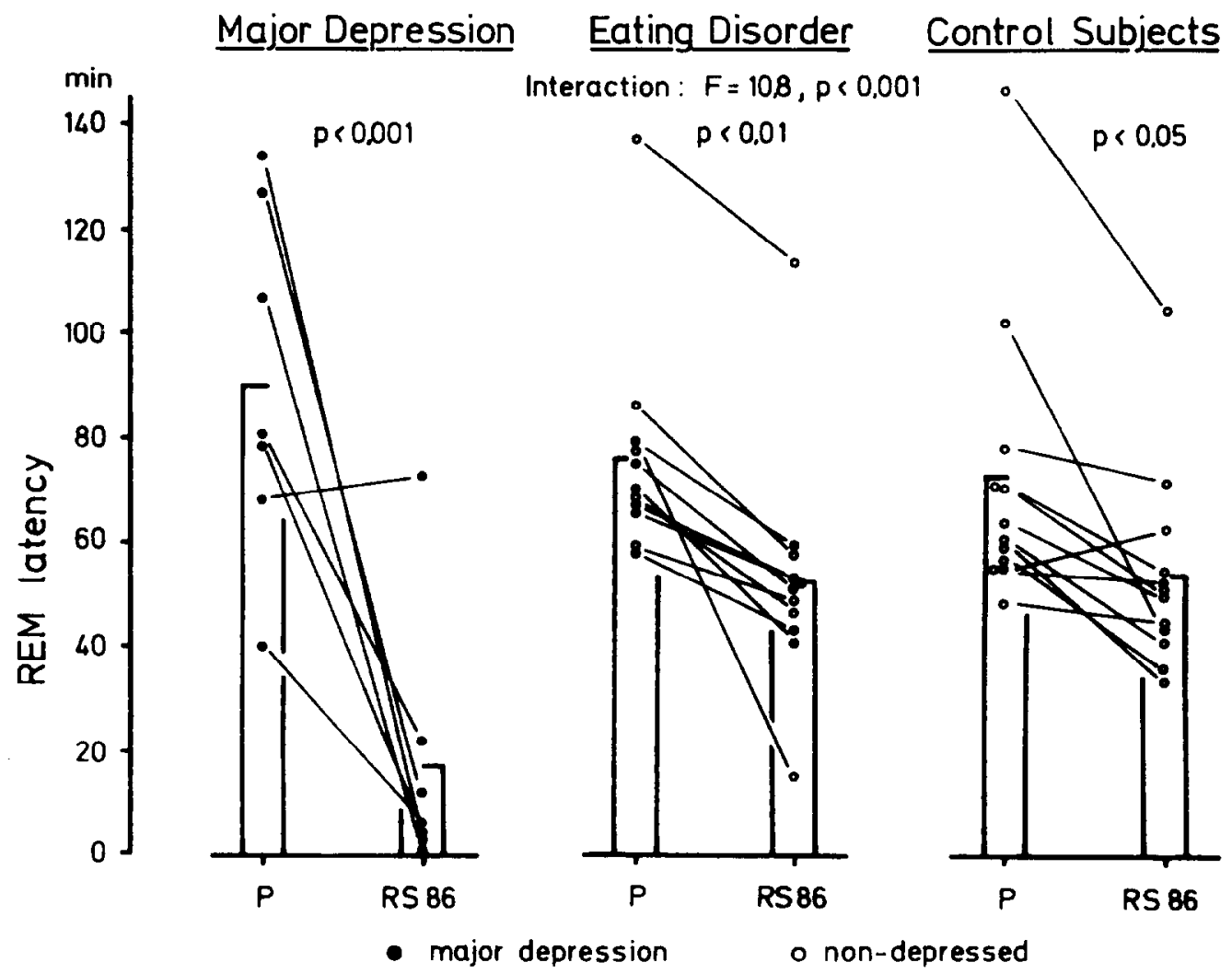

Fig. 2. REM latency during the placebo (P) and RS 86 nights in seven patients with major depression, 12 eating disorder patients, and 12 healthy volunteers. The bars indicate the means.

$81 \pm 31 \mathrm{~min} ; P<0.65)$ as well as during the drug night $(50 \pm 7$ vs. $56 \pm 32 \mathrm{~min} ; P<0.75)$.

\section{Discussion}

The one-night baseline EEG sleep of patients with melancholic depression, patients with eating disorder, and healthy subjects was found to be by and large indistinguishable. The only sleep measurement differentiating among the groups was the REM density which was increased in the depressed patients. Contrary to expectation, mean REM latency - one of the most robust biological markers for major depression - did not differ among the groups investigated. These observations did not change when dichotomizing the eating disorder patients according to the presence/ absence of a concomitant major depressive episode or on the basis of severity of depressive symptomatology. The patients with a major de- pression, however, were significantly more sensitive to cholinergic REM induction than the eating disorder patients and the healthy volunteers.

The observation of similar baseline EEG sleep measurements in patients with a major depression, melancholic subtype, and in healthy subjects seems to be not in line with the EEG sleep alterations often reported in this disorder (for overview see Gillin et al., 1984; Reynolds and Kupfer, 1987). Due to the relatively small sample sizes in the present study one might view these 'negative' findings as a type II statistical error. However, one also has to take into consideration that in the present study, the oldest patient was 27 years, whereas the depressed patients in the majority of published investigations were middle-aged. Several recent polysomnographic studies performed in juvenile and adolescent depressives give evidence that in the majority of these patients the allegedly typical REM sleep alterations are not present (e.g., 
Taub et al., 1978; Hawkins et al., 1985; Goetz et al., 1987; Appclboom-Fondu et al., 1988; Kcmpcnaers et al., 1988; Kupfer et al., 1989). In a retrospective analysis of the EEG sleep patterns of 70 depressed inpatients and of 40 healthy volunteers, ranging in age from 18 to 65 years, we demonstrated that the polysomnograms of the depressives and the control subjects were by and large indistinguishable up to the middle of the fourth decade of life (Lauer et al., 1987). In addition, several authors reported a close link between increasing age and EEG sleep alterations in major depression indicating a 'premature aging' of the sleep regulating mechanisms in this disorder (Ulrich et al., 1980; Gillin et al., 1981; Kupfer et al., 1986; Lauer et al., in preparation). The similarity of the EEG sleep patterns in the depressives and in the healthy volunteers observed in the present study, therefore, might be mainly due to the young age of the patients, thus disguising the proposed depression-associated disturbances in the basic processes regulating sleep, i.e., REM sleep.

Contrasting the polysomnograms of patients with anorexia nervosa, with bulimia nervosa, and with major depression, no significant differences in sleep parameters were observed. The only exception was a significantly increased REM density in the patients with major depression. These observations are in line with the findings of Hudson et al. (1987) obtained in outpatients with bulimia and major depression. Since the issue of EEG sleep patterns in the patients with anorexia nervosa and bulimia nervosa as well as in the healthy subjects was recently addressed in detail by us (Lauer et al., 1988), it will not be a subject of the present paper. In regard to 'depression-like' sleep alterations in eating disorder patients, particularly of REM sleep, the present study yielded completely 'negative' findings. Neither the dichotomizing of the samples according to operational diagnostic criteria (concomitant major depressive episode) nor according to the observer ratings (severity of depressive symptomatology) led to significant differences in EEG sleep measurements within the eating disorder groups. Furthermore, the sleep patterns of the dichotomized patient samples were quite similar to that found in the control subjects. Finally, the REM density -- the only EEG sleep parameter which tended to be increased in the patients with major depression when compared to the healthy volunteers - was significantly lower in the eating disorder patients than in the patients with major depression. The failure to observe a reduced REM latency in the eating disorder patients is in line with the findings of Levy et al. (1987, 1988) and Hudson et al. (1987). Others, however, reported a shortened REM latency in at least a subgroup of anorexic and bulimic patients (Neil et al., 1980; Katz et al., 1984; Walsh et al., 1985). Besides some methodological shortcomings of the latter three studies (for discussion see Lauer et al., 1988), one also has to consider the concept of a 'biological scar' to explain the discrepancies in results. This concept attributes the EEG sleep alterations in major depression to disturbances in sleep regulating systems irreversibly acquired during a previous depressive episode (Holsboer, 1988). Unfortunately, neither Katz et al. (1984) nor Walsh et al. (1985) gave information about the occurrence of lifetime diagnoses of major depression in the patients investigated. In the present eating disorder sample, four patients displayed a previous episode of major depression, their REM latencies during the acute period of eating disorder, however, were well within the norm. Not only this observation but also several further studies reporting a normalization of EEG sleep patterns in remitted depressives (Kerkhofs et al., 1985; Knowles et al., 1986; Schulz, 1988; Riemann et al., 1989) do not support the concept of a biological scar. On the other hand, Rush et al. (1986) and Steiger et al. (1989) observed a continuation of altered EEG sleep patterns in remitted depressed patients favoring this hypothesis.

Whereas on average the baseline EEG sleep in the groups investigated was by and large indistinguishable, there were some - at least discrete indices of altered sleep patterns in the young melancholic depressives. In this patient sample a shortened REM latency was found more often although the mean REM latency did not differ than in the eating disorder patients and in the control subjects. In addition, the melancholic depressives tended to display an increased REM density when compared to the healthy subjects; in comparison to the eating disorder patients, this difference was statistically significant. In other 
words, some young depressed patients exhibited REM sleep alterations typical of depression and others did not. In some studies investigating juvenile and adolescent depressives the characteristic REM sleep abnormalities (Lahmeyer et al., 1983; Emslie et al., 1987) or at least an increased REM density (Cashman et al., 1986) were reported. These observations suggest that age is not the only determining factor in the occurrence of the altered sleep patterns in major depression. According to the cholinergic-aminergic imbalance theory of depression (Janowsky et al., 1972) and the neurochemical model of slecp regulation (McCarley, 1982; Hobson et al., 1986), it seems plausible to assume in young depressives too an increased - but still subthreshold - functional activity of the REM sleep triggering cholinergic transmitter system. This assumption is supported by the observation that the sensitivity of young depressed patients to cholinergic REM induction by RS 86 seems to be similar to that of elderly depressives, although the baseline (placebo) REM latencies in the young depressives were found to be significantly longer than in the elderly patients (Lauer et al., 1987; Berger et al., 1989).

Observing a comparable RFM sleep initiating effect of RS 86 in eating disorder patients would favor the proposed biological link between eating disorder and major depression. However, the results of the present study do not support such an assumption. In all samples, a significant shortening of REM latency was observed after the administration of RS 86. This effect was, however, clearly much more marked in the patients with a major depression. In the eating disorder patients (with or without a concomitant major depressive episode) and the healthy volunteers the shortening of REM latency was similar, indicating no differences between these groups in the sensitivity of the REMregulating system to a cholinergic stimulus. Sitaram et al. (1984), on the other hand, reported a significantly higher proportion of RIT responders in anorexic patients with a current major depressive episode than in anorexics without such an additional diagnosis. Differences in methods (Sitaram et al. applied the arecoline paradigm; in the present study the RS 86 regime was used) and in the patient selection criteria (the depressed anorexics in the study by Sitaram et al. all had a personal and/or family history of affective illness; in the present RIT only one bulimic patient had a lifetime diagnosis of major depression) may contribute mainly to the differing observations.

On the basis of our findings, we conclude that by means of polysomnographic measurements during baseline conditions a differentiation is hardly possible between young depressed patients or, more generally, among young psychiatric patients and healthy volunteers. Nevertheless, the relative overactivity of the cholinergic transmitter system held responsible for the REM sleep dysregulation in depression seems to be present in young depressives too, but at a subthreshold level not obviously affecting haseline FEG sleep. This threshold, however, can be overcome by administering a cholinergic agent, i.e., RS 86. On the other hand, in eating disorder patients, with or without a concurrent major depressive episode, no hint was found of an increased sensitivity of the central cholinergic transmitter system, contradicting the assumption of a significant biological link between eating disorder and major depression.

\section{References}

American Psychiatric Association (1987) Diagnostic and Statistical Manual of Mental Disorders, 3rd edn. rev. American Psychiatric Association, Washington, DC.

Appelboom-Fondu, J., Kerkhofs, M. and Mendlewicz, J. (1988) Depression in adolescents and young adults - polysomnographic and neuroendocrine aspects. J. Affect. Disord. 14, 35.

Berger, M., Doerr, P., Lund, R., Bronisch, T. and von Zerssen, D. (1982) Neuroendocrinological and neurophysiological studies in major depressive disorders. Are there biological markers for the endogenous subtype? Biol. Psychiatry 17 1217.

Berger, M., Höchli, D., Zulley, J., Lauer, C. and von Zerssen, D. (1985) Cholinomimetic drug RS 86, REM sleep, and depression. Lancet i, 1385 .

Berger, M., Riemann, D., Höchli, D. and Spiegel, R. (1989) The cholinergic REM-sleep-induction-test with RS 86: stateor trait-marker of depression? Arch. Gen. Psychiatry 46, 421.

Cashman, M.A., Coble, P., McCann, B.S., Taska, L., Reynolds, C.F. and Kupfer, D.J. (1986) Sleep markers for major depressive disorder in adolescent patients. Sleep Res. 15, 91.

Emslie, G.F., Roffwarg, H.P., Rush, A.J., Weinberg, W.A. and Parkin-Feigenbaum, L. (1987) Sleep EEG findings in depressed children and adolescents. Am. J. Psychiatry 144. 668. 
Feighner, J.P., Robins, E., Guze, S.B., Woodruff, R.A., Winokur, G. and Munoz, R. (1972) Diagnostic criteria for use in psychiatric research. Arch. Gen. Psychiatry 26, 57.

Feinberg, I., Koresko, L. and Heller, N. (1967) EEG sleep patterns as a function of normal and pathological aging in man. J. Psychiatr. Res. 5, 107.

Gillin, J.C., Duncan, W.C., Murphy, D.L., Post, R.M., Wehr, T.A., Goodwin, F.K., Wyatt, R.J. and Bunney, W.E. (1981) Age-related changes in sleep in depressed and normal subjects. Psychiatr. Res. 4, 73.

Gillin, J.C., Sitaram, N., Wehr, T., Duncan, W., Post. R., Murphy, D.L., Mendelson, W.B., Wyatt, R.J. and Bunney, W.E. (1984) Sleep and affective illness. In: R.M. Post and J.C. Ballenger (Eds.), Neurobiology of Mood Disorders. Williams and Wilkins, Baltimore, MD, pp. 157-189.

Goetz, R.R., Puig-Antich, J., Ryan, N., Rabinovich, H., Ambrosini, P.J., Nelson, B. and Ktawiec, V. (1987) Electroencephalographic sleep of adolescents with major depression and normal controls. Arch. Gen. Psychiatry 44, 61.

Hawkins, D.R., Taub, J.M. and Van de Castle, R.L. (1985) Extended sleep (hypersomnia) in young depressed patients. Am. J. Psychiatry 142, 905.

Hobson, J.A., McCarley, R.W. and Wyzinski, P.W. (1975) Sleep cycle oscillation: reciprocal discharge by two brainstem neuronal groups. Science 189, 55.

Hobson, J.A., Lydic, R. and Baghdoyan, H.A. (1986) Fvolving concepts of sleep cycle generation: from brain centers to neuronal populations. Behav. Brain Sci. 9, 371.

Holsboer, F. (1988) Implications of altered limbic-hypothalamic-pituitary-adrenocortical (LHPA)-function for neurobiology of depression. Acta Psychiatr. Scand. 77 (Suppl. 341). 72.

Hudson, J.I., Pope, H.G., Jonas, J.M., Stakes, J.W., Grochocinski, V., Lipinski, J.F. and Kupfer, D.J. (1987) Sleep EEG in bulimia. Biol. Psychiatry 22, 820 .

Janowsky, D.S., El-Yousef, M.K., Davis, J.M. and Sekerke, H.J. (1972) A cholinergic-noradrenergic hypothesis of mania and depression. Lancet ii, 632 .

Katz, J.L., Kuperberg, A., Pollack, C.P., Walsh, B.T., Zumoff, B. and Weiner, H. (1984) Is there a relationship between eating disorder and affective disorder? New evidence from sleep recordings. Am. J. Psychiatry 141, 753.

Kempenaers, C., Kerkhofs, M., Linkowski, P. and Mendlewicz, J. (1988) Sleep EEG variables in young schizophrenic and depressive patients. Biol. Psychiatry 24, 828.

Kerkhofs, M., Hoffman, G., De Martelaere, V., Linkowski, P. and Mendlewicz, J. (1985) Sleep EEG recordings in depressive disorders. J. Affect. Disord. 9, 47.

Knowles, J.B., Cairns, J., MacLean, A.W., Delva, N., Prowse, A., Waldron, J. and Letemendia, F.J. (1986) The sleep of remitted bipolar depressives: comparison with sex- and age-matched controls. Can. J. Psychiatry 31, 295.

Kupfer, D.J., Coble, P., Kane, J., Petti, T. and Conners, C.K. (1979) Imipramine and EEG sleep in children with depressive symptoms. Psychopharmacology 60, 117

Kupfer, D.J., Reynolds, C.F., Ulrich, R.F. and Grochocinski, V.J. (1986) Comparison of automated REM and slow-wave sleep analysis in young and middle-aged depressed subjects. Biol. Psychiatry 21, 189.
Kupfer, D.J., Frank, E. and Ehlers, C.L. (1989) EEG sleep in young depressives: first and second night effects. Biol. Psychiatry 25, 87.

Lahmeyer, H.W., Poznanski, E.O. and Bellur, S.N. (1983) EEG sleep in depressed adolescents. Am. J. Psychiatry 140, 1150.

Lauer, C., Riemann, D. and Berger, M. (1987) Age, REM sleep, and depression. Sleep Res. 16, 283.

Lauer, C., Zulley, J., Krieg, J.C., Kiemann, D. and Berger, M. (1988) EEG sleep and the cholinergic REM induction test in anorexic and bulimic patients. Psychiatr. Res. 26, 171.

Levy, A.B., Dixon, K.N. and Schmidt, H.S. (1987) REM and delta sleep in anorexia nervosa and bulimia. Psychiatr. Res. $20,189$.

Levy, A.B., Dixon, K.N. and Schmidt, H. (1988) Sleep architecture in anorexia nervosa and bulimia. Biol. Psychiatry 23, 99.

Lorr, M., Klett, C.C., McNair, D.M. and Lasky, J.J. (1962) Inpatient Multidimensional Psychiatric Scale (IMPS). Consulting Psychologist Press, Palo Alto, CA.

McCarley, R.W. (1982) REM sleep and depression: common neurobiological control mechanisms. Am. J. Psychiatry 139, 565.

Metropolitan Life Insurance Company (1959) Stat. Bull. Met. Life Insur. Co. 40, 1.

Neil, J.F., Merikangas, J.R., Foster, F.G., Merikangas, K.R., Spiker, D.G. and Kupfer. D.J. (1980) Waking and all-night sleep EEG's in anorexia nervosa. Clin. Electroencephal. 11, 9.

Palacios, J.M., Bollinger, G., Closse, A., Enz, A., Gmelin, G. and Malanowski, J. (1986) The pharmacological assessment of RS 86 (2-ethyl-8-methyl-2,8-diazaspiro-(4,5)-decan-1,3dion hydrobromide). A potent, specific muscarinic acetylcholine receptor agonist. Eur. J. Pharmacol. 125, 45.

Pfanzag1, I. (1962) Allgemeine Methodenlehre der Statistik. Vol. 1. De Gruyter, Berlin.

Puig-Antich, J., Goetz, R., Hanlon. C., Davies, M., Thompson, J., Chambers, W.J., Tabrizi, M.A. and Weitzman, E.D. (1982) Sleep architecture and REM sleep measure in prepubertal children with major depression. Arch. Gen. Psychiatry 39,932 .

Rechtschaffen, A. and Kales, A. (Eds.) (1968) A Manual of Standardized Terminology, Techniques, and Scoring System for Sleep Stages of Human Subjects. Department of Health, Education, and Welfare, Washington, DC

Reynolds, C.F. and Kupfer, D.J. (1987) Sleep research in affective illness: state of the art circa 1987. Sleep 10, 199.

Riemann, D. and Berger. M. (1989) EEG sleep in depression and in remission and the REM sleep response to the cholinergic agonist RS 86. Neuropsychopharmacology 2, 145 .

Riemann, D., Joy, D., Höchli, D., Lauer, C., Zulley, J. and Berger, M. (1988) Influence of the cholinergic agonist RS 86 on normal sleep: sex and age effects. Psychiatr. Res. 24, 137.

Rush, A.J., Erman, M.K., Giles, D.E., Schlesser, M.A., Carpenter, G., Vasavada, N. and Roffwarg, H.P. (1986) Polysomnographic findings in recently drug-free and clinically remitted depressed patients. Arch. Gren. Psychiatry 43 , 878 . 
Russell, G. (1983) Anorexia nervosa and bulimia nervosa. In: G. Russell and L. Hersov (Eds.), Handbook of Psychiatry, Vol. 4. Cambridge University Press, Cambridge, pp. 285-298.

Schulz, H. (1988) Sleep in affective disorders. An experimental study in depressed and remitted patients. In: S. Smirne, M. Franceschi and L. Ferini-Strambi (Eds.), Sleep in Medical and Neuropsychiatric Disorders. Masson, Milan, pp. 75-86.

Semler, G., Wittchen, H.U., Joschke, K., Zaudig, M., Geiso, T., Kaiser, S., von Cranach, M. and Pfister, H. (1987) Test-retest reliability of a standardized psychiatric interview (DIS/CIDI). Eur. Arch. Psychiatry Neurol. Sci. 236, 214.

Sitaram, N., Gillin, J.C. and Bunney, W.E. (1984) Cholinergic and catecholaminergic receptor sensitivity in affective illness: strategy and theory. In: R.M. Post and J.C. Ballenger (Eds.), Neurobiology of Mood Disorders. Williams and Wilkins, Baltimore, MD, pp. 629-651.

Spiegel, R. (1981) Sleep and sleeplessness in advanced age. In: E.D. Weitzman (Ed.), Advances in Sleep Research, Vol. 5. Spectrum, New York.

Spiegel, R. (1984) Effects of RS 86, an orally acting cholinergic agonist, on sleep in man. Psychiatr. Res. 11, 1.

Steiger, A., von Bardeleben, U., Herth, T. and Holsboer, F.
(1989) Sleep EEG and nocturnal secretion of cortisol and growth hormone in male patients with endogenous depression before treatment and after recovery. J. Affect. Disord. 16,189

Strober, M. and Katz, J.L. (1987) Do eating disorders and affective disorders share a common etiology? A dissenting opinion. Int. J. Eating Disord. 6, 171.

Swift, W.J., Andrews, D. and Barklage, N.E. (1986) The relationship between affective disorder and eating disorder: a review of the literature. Am. I. Psychiatry 143, 290.

Taub, J.M., Hawkins, D.R. and Van de Castle, R.L. (1978) Electrographic analysis of the sleep cycle in young depressed patients. Biol. Psychiatry 7, 203.

Ulrich, R.F., Shaw, D.H. and Kupfer, D.J. (1980) Effects of aging on EEG sleep in depression. Sleep 3, 31.

Walsh, B.T., Goetz, R., Roose, S.P., Fingeroth, S. and Glassman, A.H. (1985) EEG-monitored sleep in anorexia nervosa and bulimia. Biol. Psychiatry 20, 947.

Young, W., Knowles, J.B., MacLean, A.W., Boag, L. and McConville, B.J. (1982) The sleep of childhood depressives: comparison with age-matched controls. Biol. Psychiatry 17, 1163. 